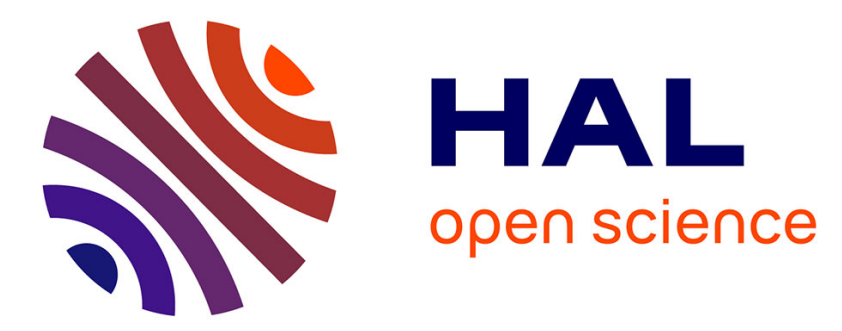

\title{
Formulation of solid products: two-component tablets with a disintegrating agent
}

\author{
S Hutin, Philippe Accart, Driss Oulahna, John A. Dodds
}

\section{To cite this version:}

S Hutin, Philippe Accart, Driss Oulahna, John A. Dodds. Formulation of solid products: twocomponent tablets with a disintegrating agent. Polymer international, 2003, 52 (4), pp.581-585. 10.1002/pi.1194 . hal-01626711

\section{HAL Id: hal-01626711 https://hal.science/hal-01626711}

Submitted on 23 Feb 2018

HAL is a multi-disciplinary open access archive for the deposit and dissemination of scientific research documents, whether they are published or not. The documents may come from teaching and research institutions in France or abroad, or from public or private research centers.
L'archive ouverte pluridisciplinaire HAL, est destinée au dépôt et à la diffusion de documents scientifiques de niveau recherche, publiés ou non, émanant des établissements d'enseignement et de recherche français ou étrangers, des laboratoires publics ou privés. 


\title{
Formulation of solid products: two-component tablets with a disintegrating agent
}

\author{
S Hutin, P Accart, D Oulahna and JA Dodds* \\ Laboratoire de Génie des Procédés des Solides Divisés, UMR-CNRS 2392, Ecole des Mines d'Albi Carmaux, Campus Jarlard, 81013 Albi, \\ France
}

\begin{abstract}
The formulation of binary tablets containing an insoluble powder and a disintegrating agent is examined from the point of view of the particle packing theory in terms of the relative size and proportion of the two components. A relationship is found between the overall porosity and the crush resistance, and between the contacts between particles and the disintegration time. Tablets made with an industrial tablet press for three different systems, caffeine-starch, cocoa-ultrafine sugar and cocoa-icing sugar, were tested for crush resistance and disintegration time. The results followed the theoretical predictions.
\end{abstract}

Keywords: formulation; tablets; crush resistance; disintegration time; porosity; contact coordination

\section{INTRODUCTION}

Solid products are usually mixtures in the form of granules, extrudates, tablets or even free powder, which are formulated to provide the end-use properties required by consumers. As in the formulation of liquids or emulsions, the primary requirement is to establish the correct dose of each ingredient for the required function, and to ensure their mutual chemical compatibility. The second stage is to assemble the ingredients in a structure to provide the end-use properties of stability, handling, dispersability, etc. In practice, product design is usually based on experience and empirical methods, with new products developed by small modifications to existing formulas. This means that formulation methods are difficult to transmit to others, are nonconducive to innovation, and leave little room for the development of an ordered body of information about product design. Another consequence is that formulas tend to become more and more complex, involving more and more components, the overall utility of which are difficult to establish (see Schorsch ${ }^{1}$ ).

In other fields of technology, the analytical approach has been found to be useful. By this method, complex systems have been simplified to find their inherent substructure which has lead to better understanding and permits generalisations. It may be supposed that this could be the case for solids product design. It is probable that practical formulations involving many components pose too complex a problem for simple analysis, in which case multi-dimensional parameter analysis, (eg Brooks $e t a l^{2}$ ) may give more insight than trying to break down the problem into simpler units. In addition, the processing method used to obtain a given solid product has obviously a very important effect on product characteristics, eg granules produced by spray drying differ considerably from those produced by high shear granulation. A product in the form of a tablet can be very different from the same product produced by extrusion.

Despite these complications, and as a first simple approach, it can be observed that all solid products are formed from individual grains assembled together in a structure, which depends on the relative sizes, shapes and quantities of the individual grains. By examining this geometrical structure it may be possible to give some general rules for product design. As an example we consider here the formulation of tablets composed of an insoluble active product and a hydrophilic disintegration promoter. Two geometrical properties are considered: (1) the compacity (or porosity) of the mixture is assumed to determine mechanical strength; (2) the types of contact between the particles are assumed to determine the structural nature of the powder mixture and the ease of disintegration. The variation of porosity (or compacity) and the variation of contacts between particles as function of particle size and mixture composition are examined theoretically and experimentally. Results are presented for tablets made from caffeine-starch mixtures and cocoa-sugar mixtures. 


\section{TABLETS FORMED FROM TWO COMPONENTS} Two components with the same particle size

The simplest case of formulation, when two powders with the same particle size are used to make tablets, is worth examining to establish some basic principles. In this case the two components, the insoluble product $\mathrm{B}$ and the disintegrating agent A may differ in colour, or chemical composition, but have the same physical properties of size, shape, density, etc. There is no geometrical interaction between the components, so that the porosity $(\varepsilon)$ and the compacity (defined as $(1-\varepsilon)$ ) do not vary with mixture, proportions. Thus, there will be no intrinsic variation in mechanical strength with mixture proportions. However, there will be variations in contacts between the two components in the mixture, and here the relative distribution of the contact types can be determined by simple statistics (Giraud, pens comm):

$$
\begin{aligned}
& t_{\mathrm{AA}}=p_{\mathrm{A}}^{2} \\
& t_{\mathrm{BB}}=\left(1-p_{\mathrm{A}}\right)^{2} \\
& t_{\mathrm{AB}} \equiv t_{\mathrm{BA}}=2 p_{\mathrm{A}}\left(1-p_{\mathrm{A}}\right)
\end{aligned}
$$

where $p_{\mathrm{A}}$ is the volume fraction of A particles and $t_{\mathrm{AB}}$ is the number fraction of contacts between A particles and $B$ particles:

$$
\begin{array}{r}
p_{\mathrm{A}}+p_{\mathrm{B}}=1 \\
t_{\mathrm{AA}}+t_{\mathrm{BB}}+t_{\mathrm{AB}}=1
\end{array}
$$

It can clearly be seen that there are two types of mixture: (1) those where the proportion of type A grains is less than $50 \%$, giving a matrix of $B$ particles with A particles dispersed in it; (2) those where there is more than $50 \%$ of A particles, and the opposite result is obtained. As would be expected, the maximum contact between dissimilar particles $t_{\mathrm{AB}}$ is at a mixture composition of $50 \%$ where $t_{\mathrm{AB}}=0.5$ and $t_{\mathrm{AA}}=t_{\mathrm{BB}}=0.25$. Consequently, when the aim of the formulation is to have an intimate mixture of the insoluble product with the disintegrating agent to give the best disintegration, it is necessary to use a mixture of $50 \% \mathrm{~A}, 50 \% \mathrm{~B}$.

\section{Two components with different particle size}

A more practical case is when the components are of different sizes, that is a mixture of large and small grains. In this case there will be a variation in porosity (or compacity) due to the smaller grains being able to fit between the larger grains and which can be expected to give a variation in the intrinsic mechanical strength of the tablets. More dense tablets will be stronger than less dense tablets. Figure 1 shows examples of the variation of porosity as a function of mixture composition calculated using a statistical geometrical model of sphere packing. ${ }^{3}$ Equations for the case of mixing very small with very large particles are also available. ${ }^{4}$ The theoretical predictions of Vshaped curves, where the minimum porosity depends only on the relative sizes and proportions of the two

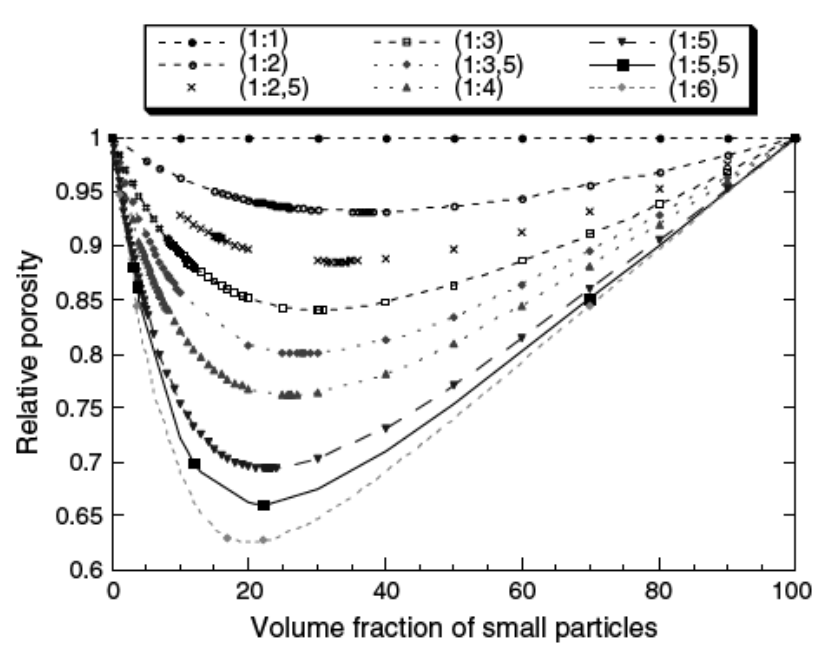

Figure 1. Variation of relative porosity $\left(\varepsilon_{\text {mixture }} / \varepsilon_{1}\right)$ with composition for a binary mixture of spheres with different sizes.

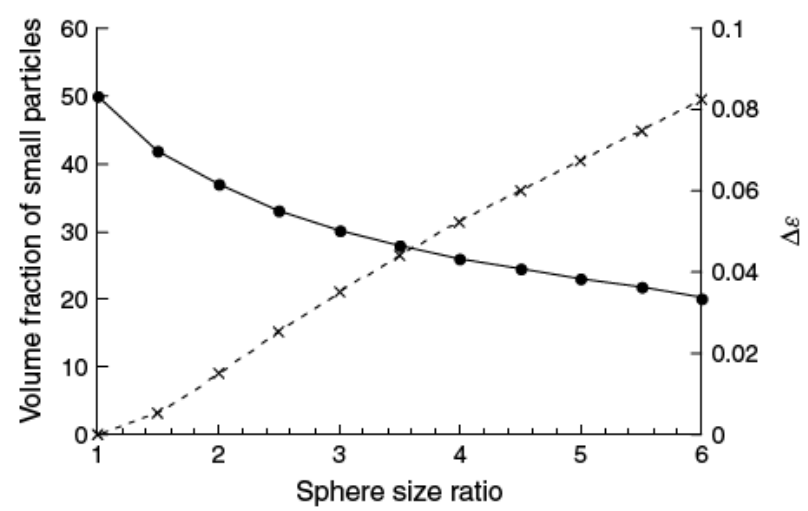

Figure 2. Locus of the minimum porosity as a function of sphere size ratio and mixture composition. $\Delta \varepsilon$ is the difference between the maximum and the minimum porosity for the mixtures.

components have been confirmed by experiment. ${ }^{5}$ Figure 2 shows, respectively, the locus of the minimum porosity and the locus of the composition giving the minimum porosity, as a function of size ratio. This curve can give some indications for optimum tablet formulation. For example, if the tablet requires say $78 \%$ of the insoluble product and $22 \%$ of disintegrating agent, then a minimum porosity and maximum tablet strength could be obtained by using a disintegrating agent with a particle size five times smaller than that of the insoluble active product. For the symmetrical case of $22 \%$ insoluble product and $78 \%$ disintegrating agent, the size ratio should be the inverse, that is 0.2 .

The statistical geometrical packing model can also be used to give the variation in contact types with mixture proportions as a function of sphere size ratio. Figure 3 shows the predictions for mixture with a size ratio of 5 . This result may be compared with eqns (1)-(3), and it can be seen that, as with the variation in porosity, the curves are very dissymmetric with a maximum in $t_{\mathrm{AB}}$ for low values of volume fraction of the small particles. Figure 4 gives the volume fraction for the maximum in dissimilar 


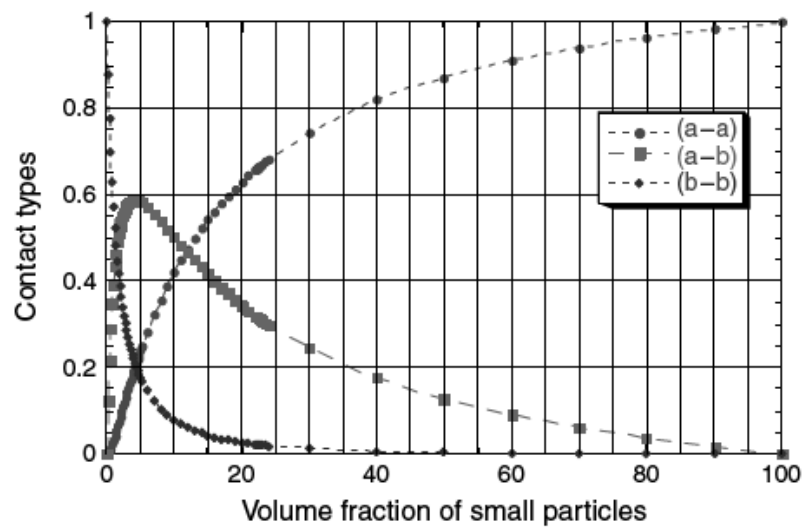

Figure 3. Contact types $a-a, b-b, a-b$, as a function of composition for binary mixtures of spheres.

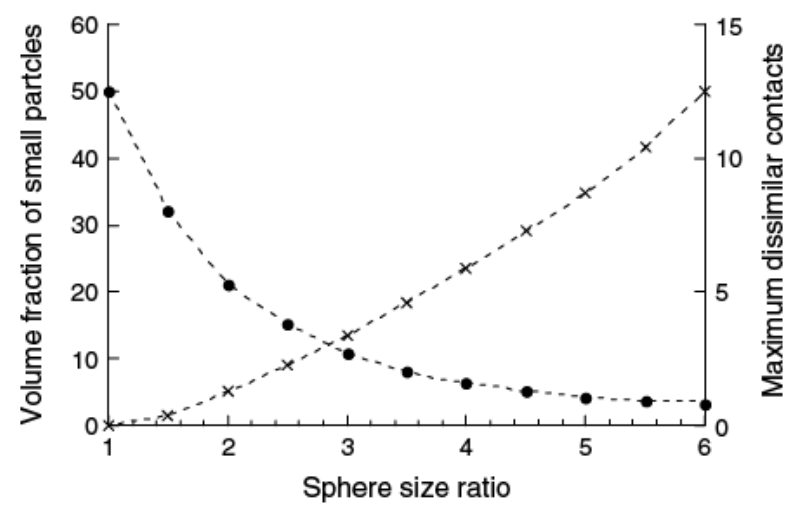

Figure 4. Locus of maximum in dissimilar $a-b$ contacts as a function of sphere size ratio and composition in binary mixtures of spheres.

contacts as a function of particle size ratio. From this it may be deduced that if a formula requires $10 \%$ of a small particle size component disintegrating agent, then the other component should have a particle size which is three times greater to ensure maximum 'mixedness'. The symmetrical problem of a large particle size disintegrating agent will require $90 \%$ with a size ratio of 0.33 . These results can be generalised for any number of components.

In the case of binary mixtures Ben Aim and LeGoff ${ }^{5}$ and Guyot-Hermann ${ }^{6}$ gave the following expressions for the composition of the mixture with a maximum of dissimilar contacts.

$$
\begin{aligned}
& \text { Critical mass composition }=0.32 \frac{\rho_{1}}{\rho_{2}} \\
& \times\left[\left(\frac{X s v_{1}}{X s v_{2}}+1\right)^{3}-1\right]
\end{aligned}
$$

In this, the indices refer to the components 1 and 2, $\rho$ is the density of the components and $X s v$ is the mean particle size by surface volume, sometimes denoted as $\mathrm{X}[3.2]$.

\section{EXPERIMENTAL}

\section{Material and methods}

To examine the applicability of the ideas given above, tablets formed by binary mixtures of caffeine and starch and also cocoa powder and sugar were made and tested. The caffeine used was a pharmaceutical grade Nr 921 obtained from Boehringer Ingelheim and sieved to pass between $400 \mu \mathrm{m}$ and $800 \mu \mathrm{m}$ mesh sizes. The starch used was StaRX $1500^{\circledR} \mathrm{Nr} 86823$ obtained from Sandoz and sieved to pass between 50 and $100 \mu \mathrm{m}$ mesh sizes. The cocoa was a standard grade supplied by Cemoi-Phoscao SA. The two sugars used were supplied by British Sugar Ltd. One was a standard icing sugar sieved to pass between 40 and $80 \mu \mathrm{m}$ mesh sizes; the other was a special product called silk sugar with a very small particle size and used as received. Observation under a microscope indicated that the particles were not spherical but could be considered to be convex as they did not have exaggerated shapes such as needles or platelets. The characteristics of the powders are given in Table 1, as determined by means of standard procedures using a Malvern 2000 Mastersizer, an Erweka tap density machine and a Micromeritics Accupyc helium pycnometer. The poured and tapped densities are determined by the standard method of pouring a measured weight of powder into a $250-\mathrm{ml}$ measuring cylinder and determining the volume both before (poured density) and after being subjected to controlled tapping (tap density).The Haussner ratio is defined as the ratio of the tapped density to the poured density. Values above 1.5 are indicative of cohesive powders.

Mixtures in various proportions of these powders were prepared in a Erweka hoop mixer with an addition of about $1 \%$ of magnesium stearate as a lubricant. Batches of about 1 litre of mixture were made into tablets with a Killian 15 punch rotary tabletting machine. These tablets were tested for compression resistance with an Eweka TBH30 crush resistance machine. The disintegration times were determined using an Eweka ZT32 disintegration tester with a sixsample basket. The standard procedure was followed, as described by Carstensen. ${ }^{7}$ This involves putting a

\begin{tabular}{|c|c|c|c|c|c|}
\hline Powder & $\begin{array}{l}\text { Surface/volume } \\
\text { diameter }(\mu \mathrm{m})\end{array}$ & $\begin{array}{l}\text { True density } \\
\qquad\left(\mathrm{g} \mathrm{ml}^{-1}\right)\end{array}$ & $\begin{array}{l}\text { Poured density } \\
\qquad\left(\mathrm{g} \mathrm{ml}^{-1}\right)\end{array}$ & $\begin{array}{l}\text { Tapped density } \\
\qquad\left(\mathrm{g} \mathrm{ml}^{-1}\right)\end{array}$ & Haussner index \\
\hline Caffeine & 27.4 & 1.420 & 0.55 & 0.57 & 1.04 \\
\hline Cocoa & 5.7 & 1.460 & 0.303 & 0.621 & 2.05 \\
\hline Icing Sugar & 11.3 & 1.590 & 0.449 & 0.925 & 2.06 \\
\hline Silk Sugar & 5.2 & 1.587 & 0.242 & 0.57 & 2.35 \\
\hline Starch & 2.6 & 1.500 & 0.61 & 0.74 & 1.21 \\
\hline
\end{tabular}

Table 1. Characteristics of the powders used in the experiments 
tablet onto the stainless steel support sieve of each tube in the basket, then placing the basket in water at $37^{\circ} \mathrm{C}$, oscillating up and down and determining the time at which no solids remain on the support grid.

\section{Experiment Results and discussion}

The three systems studied were: (1) caffeine-starch, where the particle size of the disintegrating agent is smaller than that of the insoluble component; (2) cocoa-silk sugar, where the disintegrating agent is similar in particle size to the insoluble component; (3) cocoa-icing sugar, where the particle size of the disintegrating agent is greater than that of the insoluble component. The compaction characteristics mean that it is not possible to make tablets for the whole range of composition for all the different systems. For example, tablets could not be produced with more than $70 \%$ silk sugar as they did not hold together. However a reasonable range of composition could be tested. The experimental results for crush resistance and disintegration time are given in Table 2 and in Figs 5 and 6 .

It can be seen from the results, and by crossreferencing with Fig 1, that the maximum crush resistance corresponds roughly to the composition with the minimum in porosity. That is, the maximum

Table 2. Disintegration times and crush resistance as a function of mixture composition for tablets made from (a) caffeine-starch, (b) cocoa-silk sugar, (c) cocoa-icing sugar (a)

\begin{tabular}{ccc}
\hline $\begin{array}{l}\text { Volume fraction } \\
\text { of starch }\end{array}$ & $\begin{array}{c}\text { Crush resistance } \\
(\mathrm{N})\end{array}$ & $\begin{array}{c}\text { Disintegration } \\
\text { time }(\mathrm{s})\end{array}$ \\
\hline 2.4 & 49.2 & 1759 \\
4.7 & 65.2 & 1251 \\
7.1 & 89.2 & 723 \\
9.5 & 86.6 & 100 \\
11.9 & 31.1 & 34 \\
14.3 & 83.0 & 67 \\
19.1 & 74.7 & 69 \\
38.7 & 55.8 & 58 \\
48.6 & 49.9 & 106 \\
\hline
\end{tabular}

(b)

\begin{tabular}{ccc}
\hline $\begin{array}{l}\text { Volume fraction } \\
\text { of silk sugar }\end{array}$ & $\begin{array}{c}\text { Crush resistance } \\
(\mathrm{N})\end{array}$ & $\begin{array}{c}\text { Disintegration } \\
\text { time }(\mathrm{s})\end{array}$ \\
\hline 28.3 & 24.4 & 1270 \\
38.0 & 26.4 & 1491 \\
47.9 & 37.8 & 1153 \\
58.0 & 44.6 & 1135 \\
68.2 & 52.2 & 595 \\
\hline (c) & & \\
\hline Volume fraction & Crush resistance & Disintegration \\
of icing sugar & $(\mathrm{N})$ & time (s) \\
\hline 38.0 & 0 & 1034 \\
68.2 & 26.2 & 925 \\
78.6 & 56.3 & 622 \\
89.2 & 99.6 & 362 \\
100 & 80.0 & \\
\hline
\end{tabular}

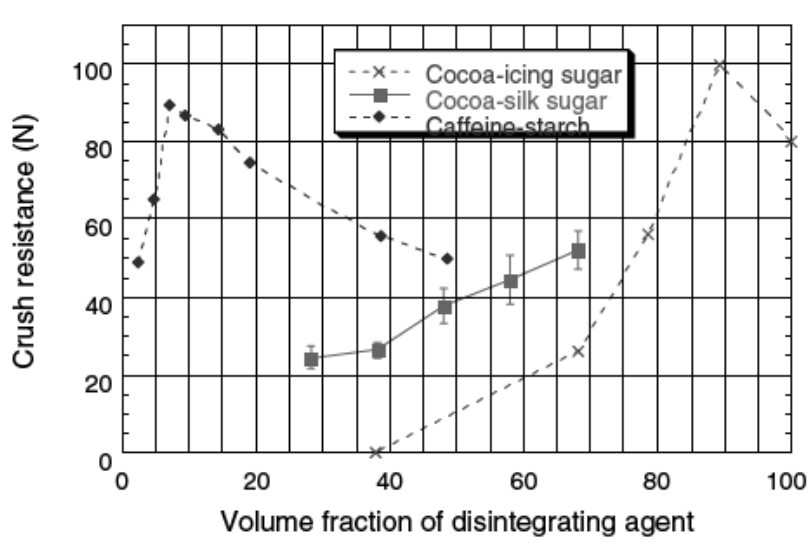

Figure 5. Crush resistance as a function of mixture composition for tablets made from caffeine-starch, cocoa-silk sugar, cocoa-icing sugar.

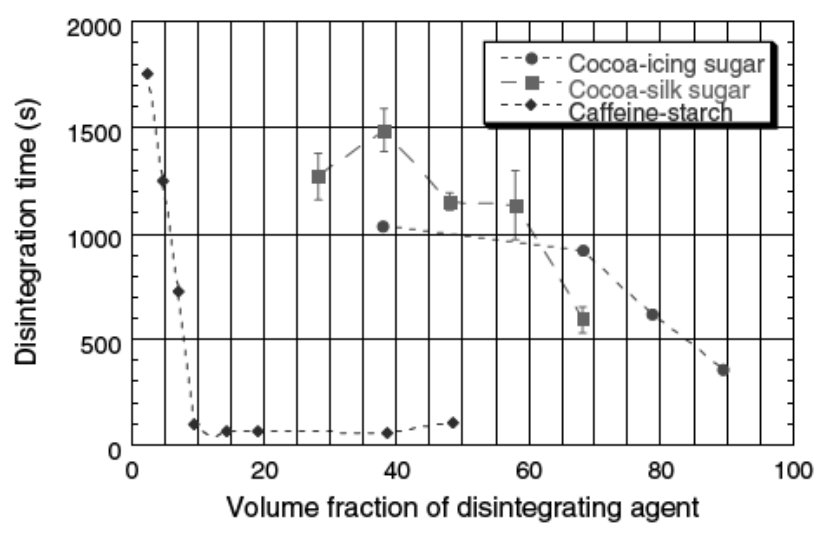

Figure 6. Disintegration time as a function of mixture composition for tablets made from caffeine-starch, cocoa-silk sugar, cocoa-icing sugar.

crush resistance is for a percentage volume of disintegrating agent less than $50 \%$ in case 1 , greater than $50 \%$ in case 3 , and there is no real variation with composition in case 2 of roughly equal sized particles. Figure 6, cross-referenced with Fig 3, shows that the results for disintegrating time correspond to the composition with the maximum in dissimilar contacts. In case 1 , the curve reaches a lower value at a composition of $10 \%$ starch. In case 2 , the curve reaches a low value for about $70 \%$ silk sugar 2 , and in case 3 tends to a low value for very high icing sugar contents.

Equation (6) can be used to calculate the following values: where $T_{d m i n}$ is the minimum disintegration time

Case 1 where $X_{\text {insol }} / X_{\text {desint }}=10.6, \mathrm{~T}_{\mathrm{dmin}}$ is at a composition of $10.5 \%$ starch;

Case 2 where $X_{\text {insol }} / X_{\text {desint }}=1.09, \mathrm{~T}_{\mathrm{dmin}}$ is at a composition of $74.6 \%$ silk sugar;

Case 3 where $X_{\text {insol }} / X_{\text {desint }}=0.51, \mathrm{~T}_{\mathrm{dmin}}$ is at a composition of $89.3 \%$ icing sugar.

and it can be seen that these predictions are in reasonable agreement with the experimental results shown in Fig 6.

It should be remembered that the tablets were prepared on an industrial rotary tablet press, and that 
the above results are average values for measurements on six tablets. For a finer analysis of the phenomena, tablets could be prepared more carefully under controlled conditions on a compression test machine. This should reduce the variability, but the intention here was to treat the more practical problem of industrial production and show that the effects were more important than the large variability. In this sense, it is clear above, that the disintegrating agent forms a continuous network of contacts which penetrates the tablets and leads to disintegration. To confirm this, Leuenberger $^{8}$ suggests that it may be necessary to make a more detailed examination of the structure of the tablets using the percolation theory.

\section{CONCLUSIONS}

The interactions between soluble solids and disintegrating agents in tablets have been examined with respect to their relative particle sizes by means of theoretical models of particle packings of spheres. The porosity of mixtures and the contacts between the different components depended on the relative particle sizes and the relative volumes of the two components and are indicative of the structure of the two-component tablets. These structural characteristics are taken to be related to usage properties such as the crush resistance and disintegration time of binary tablets.

An industrial tablet press has been used to make tablets from three different binary systems of different particle size ratios and with a range of compositions. Experimental determinations of the variation of crush resistance and disintegration times with mixture composition for three different particle size ratios are generally in agreement with the theoretical predictions despite the great simplifications involved in applying conclusions from the structures of sphere packing to real powder mixtures.

This preliminary study gives a theoretical basis for the formulation of tablets comprising two components and indicates that binary formulations should be considered in two zones of composition: as one component dispersed in the other or the opposite. The critical composition separating these two zones depends on the relative particle sizes of the components. For example, it is shown why the minor component in the mixture should always have the smaller particle size.

\section{ACKNOWLEDGEMENTS}

We would like to thank the companies Cemoi-Phoscao SA and British Sugar Ltd for providing some of the powders used in the experiments. We would also like to thank the undergraduate students of the Ecole des Mines d'Albi-Carmaux who performed some of the experiments.

\section{REFERENCES}

1 Schorsch G, L'Actualité Chimique, Dec 2000, pp 20-24.

2 Brooks R, Foo F and Rowe R, Pharma Tech Europe 12:40-50 (2000).

3 Dodds JA, $\mathcal{F}$ Colloid Interface Sci 77:317-327 (1980).

4 Dodds JA, in Powders and Solids: Developments in Handling and Processing Technologies, ed by Hoyle W, Royal Society of Chemistry, London, pp 57-69 (2001).

5 Ben Aim R and Le Goff P, Powder Technology 2:1 (1968-9).

6 Guyot-Hermann AM, STP Pharma Sciences 6:445-462 (1992).

7 Carstensen JT, Pharmaceutical Preformulation, Technomic Publishing, Lancaster (1998).

8 Leuenberger H, Advanced Powder Technology 10:323-352 (1999). 